\title{
Life cycle sustainability assessment
}

\author{
Alessandra Zamagni \\ Received: 20 January 2012 / Accepted: 9 February 2012 /Published online: 22 February 2012 \\ (C) Springer-Verlag 2012
}

\begin{abstract}
Almost 10 years have passed since the first editorial on life cycle-based methods for sustainability assessment by Klöpffer (2003). Sustainability was already a core issue on the political agenda, and this interest was also echoed at scientific levels since many approaches and methods were being proposed and developed. So what happened in the last decade, and why today do I feel the urgency to talk about sustainability assessment? There are three main considerations, which I would like to briefly present.
\end{abstract}

Firstly, a recent article by Bettencourt and Kaur (2011) provides a nice analysis of the evolution of the sustainability concept in the scientific community. The authors assembled a large body of scientific publications written between 1974 and 2010 that contain the words "sustainability" and/or "sustainable development" in their abstract, title or keywords. Overall, they came up with 20,000 papers, authored by about 37,000 authors found in 174 countries. This is a massive amount of publications, which testifies to the extraordinary growth of interest in sustainability assessment over time. These figures alone say much about how urgent and global the topic of sustainability is, and how much it has developed.

If we look more closely at these papers and select only those that contain the words "sustainability" and "LCA", we find about 600 articles. Considering the relatively young history of Life Cycle Assessment (LCA) compared with

\footnotetext{
A. Zamagni $(\bowtie)$

Italian National Agency for New Technologies,

Energy and Sustainable Economic Development (ENEA),

LCA \& Ecodesign Laboratory,

via Martiri di Monte Sole 4,

40129 Bologna, Italy

e-mail: alessandra.zamagni@enea.it
}

other methodologies, I would say that this number is equally impressive. A brief analysis of these 600 papers delivers interesting information about the growing rate of publications and the disciplines involved. The number of papers published in 2010 was three times higher than those in 2007, with major contributions from the subject areas of environmental sciences (53\%), followed by engineering (34\%), energy $(16 \%)$ and an interesting contribution by social sciences $(6.6 \%)$. These figures allow me to introduce my second and third considerations, that is, the relevance of a life cycle approach in sustainability assessment and the importance of an interdisciplinary integration, respectively.

Since sustainability is a global concept that involves present and future generations, this inevitably calls for a system-wide analysis. A system perspective is at the core of the life cycle approach, which can provide valuable support in the sustainability evaluations, as demonstrated by the numerous environmental policies at European level, which are based on the life cycle concept. Such environmental policies include the Sustainable Consumption and Production Action Plan (CEC 2008), the Waste Framework Directive (Anonymous 2006), the Thematic Strategy on the Sustainable Use of Natural Resources (CEC 2005) and the Environmental Technologies Action Plan (CEC 2004), to mention just a few. Developed and standardised firstly for evaluating the potential environmental impacts of goods and services, LCA evolved over time, becoming more suitable for sustainability evaluations. First attempts date back to 1998 when Andersson et al. (1998) examined the feasibility of incorporating the concept of sustainability principles in each phase of LCA.

Later, in 2000, The Natural Step approach was proposed (Upham 2000), which includes sustainability principles to inform LCA impact categories, and uses backcasting in the LCA framework. These approaches highlighted the need for 
a perspective that was wider than LCA, as proposed later by Hunkeler and Rebitzer (2005), and formalised into the Life Cycle Sustainability Assessment (LCSA) framework (Klöpffer 2008), where the LCSA $=\mathrm{LCA}+\mathrm{LCC}+\mathrm{S}-$ LCA. LCC and S-LCA refer to Life Cycle Costing and Social Life Cycle Assessment, respectively. This is the present state of the art of life cycle-based sustainability assessment, which represents an advancement compared to 10 years ago. In fact, S-LCA has been sketched at a methodological level (Benoît et al. 2010; Benoît and Mazijn 2009), and initial case studies are being published. A Code of Practice on LCC was published at the beginning of the year (Swarr et al. 2011), together with the more recent publication of the LCSA framework by UNEP/SETAC (Valdivia et al. 2011) and related applications (Finkbeiner et al. 2010). In parallel, LCA has also evolved. Approaches to time modelling, consequential LCA, hybrid approaches combining LCA and input-output analysis, new impact categories and indicators and characterization factors are only some examples of the developments the LCA methodology is going through.

These developments in the LCA fields have been occurring by using LCA in combination/integration with economic models, ecological models and social theories. This is in line with LCA's inherent transdisciplinary nature, since its framework historically works also with the support of other models and disciplines, as clearly demonstrated in the impact assessment phase.

This leads to the third consideration: the importance of integration. Sustainability is characterised by complexity (multi-disciplinary knowledge, multi-spatial and time scales), uncertainty (many variables, poor information and data availability) and urgency (urgency of actions towards challenges like climate change). None of the methods available can address all of these aspects alone, as showed by the many approaches proposed in different disciplinary areas. An interdisciplinary integration is necessary (Bruins et al. 2010; Seager 2008), defined as "the activity of critically evaluating and creatively combining ideas and knowledge to form a new whole or cognitive advancement. It contributes to solving complex problems by providing a systematic approach to combining and interrelating insights grounded in commonalities while taking into account differences" (Bruins et al. 2010). Kates et al. (2001), in introducing the concept of sustainability science, clarified that it differs notably from science as we know it, aimed at understanding the fundamental interactions between nature and society. Sustainability science recognises the multiple facets of sustainability problems, which span across the full range of scales from local to global, accounting for both temporal inertia and urgency of processes, which calls for the knowledge input of different disciplinary fields.
The LCSA framework as defined above provides a good starting point for integration. Being fully aware of the contrast between the complexity of the problem-with nonlinearities and dynamic features - and the way in which we presently address it with the life cycle methods-with linear and steady-state models - the framework provides a first setting for starting sustainability assessment in the dayby-day practice, in particular, at micro (product system) level. Going beyond the present state of the art, the need exists to address complexities and sustainability questions along the full range of scales, from local to global. Moreover, it is necessary to investigate mechanisms and relationships, which presently are not included in the LCSA framework since the three methods are applied independently one from another under specific consistency requirements, but without considering the mutual relations which can arise. The understanding of the interrelations among the different components of sustainability—encompassing at minimum environmental, economic and social dimensions, but also including governance or even manufactured and financial (Parkin et al. 2000), or considering a vision of worth living integrated development (Koroneos and Rokos 2012) - needs to be considered. In fact, "the combined impacts, positive and negative, of the sets of measures as a whole, are likely to be more than the simple sum of the impacts of their constituent measures because of synergistic effects" (Lee and Kirkpatrik 2001).

Mechanisms are connecting links between activities, and as such, they can show up everywhere, involving a variety of domains and giving rise to different consequences, as demonstrated by Graedel and van der Voet (2010) in relation to the environmental aspects. For example, market mechanisms are part of broader economic mechanisms, which recall concepts like employment and growth. These in turn function within a cultural, social, political and regulatory context. Taking them into account requires the use of different models, borrowed also from macroeconomic theory (in line with the present developments on Consequential LCA), and which models to use and how to apply them is an open question for the researchers.

Attempts to address such complexities have been proposed, for example, with the development of a Life Cycle Sustainability Analysis framework (Guinée et al. 2011), which is a transdisciplinary integration framework of models, able to accommodate knowledge from different disciplines relevant to sustainability and better link questions to models of analysis. A similar approach was proposed by Halog and Manik (2011), who also introduced multi-criteria analysis and dynamic system modelling. However, more research is necessary to make these frameworks operational.

Coming back to my initial question, it is clear that the growing interest in sustainability assessment at many levels in society, the role played by the life cycle concept in such 
evaluations and the great development of the LCA methodology that has been occurring in the last years-which broadened its boundaries to include economic and social aspects, but also increased the sophistication of its modelling-justify the need for a new subject area in the International Journal of Life Cycle Assessment, namely Life Cycle Sustainability Assessment. We invite practitioners and method developers to submit articles addressing the full range of sustainability-related topics, in particular, with reference to the following aspects:

- How can the LCSA framework be consistently applied, considering also the different degree of maturity of the three methods? Is the consistency requirement (same system boundary) always feasible and conceptually correct or do we need to set other criteria? Which difficulties have been encountered in applying the framework?

- What role does scenario modelling play in the LCSA framework?

- How can LCSA move from three separate assessments, carried out under consistency requirements, to what Klöpffer (2008) defined as LCSA = "LCA new", which would consists of one Life Cycle Inventory to be followed by up to three impact assessments, possibly leading to the same set of areas of protection? What other approaches to LCSA can be proposed?

- What approaches exist for including mechanisms in the analysis? How can different domains, normative positions (values) and empirical knowledge be dealt with? How can future changing structures of the economy be accounted for? And what kind of methods and tools can be used, combined and/or integrated?

- What do we need to further develop LCSA? What research strategies and lines are considered relevant?

- How can uncertainty, which is an inevitable and inherent characteristic of sustainability assessment, be accommodated and managed?

Case studies, methodological developments, discussions about data availability, and thus how the present software tools can deal with such evaluation are encouraged.

Moreover, a special issue on LCSA is also in preparation, which will be edited by the end of this year, as a contribution to and acknowledgment of the Rio +20 meeting, and all practitioners are warmly invited to submit contributions. ${ }^{1}$ I hope this new section will provide a lively platform for discussion and for achieving important developments which are even more needed in such a challenging and complex world.

\footnotetext{
${ }^{1}$ The call for papers for the special issue and the instructions for the authors are available at the Springer website: www.springer.com.
}

\section{References}

Andersson K, Eide MH, Lundqvist M, Mattsson B (1998) The feasibility of including sustainability in LCA for product development. J Clean Prod 6(3-4):289-298

Anonymous (2006) Directive 2006/12/EC of the European Parliament and of the Council of 5 April 2006 on waste. Official Journal of the European Union. L114. 27.4.2006: 9-21

Benoît C, Mazijn B (eds) (2009) Guidelines for social life cycle assessment of products. Paris. pp 104. Downloaded from: http:// lcinitiative.unep

Benoît C, Norris GA, Valdivia S, Ciroth A, Moberg A, Bos U, Prakash S, Ugaya C, Beck T (2010) The guidelines for social life cycle assessment of products: just in time! Int J Life Cycle Assess 15(2):156-163

Bettencourt LMA, Kaur J (2011) Evolution and structure of sustainability science. Proc Nat Acad Sci (USA) 108(49):19540-19545

Bruins RJF, Munns WR, Botti SJ, Brink S, Cleland D, Kapustka L, Lee D, Luzadis V, McCarthy LF, Rana N, Rideout DB, Rollins M, Woodbury P, Zupko M (2010) A new process for organizing assessments of social, economic, and environmental outcomes: case study of wildland fire management in the USA. Integrated Environ Assess Manag 6(3):469-483

CEC (Commission of the European Communities) (2004) Communication from the Commission to the European Parliament, the Council, the European Economic and Social Committee and the Committee of the Regions Stimulating Technologies for Sustainable Development: an environmental technologies action plan for the European Union. COM(2004) 38 final

CEC (2005) Communication from the Commission to the European Parliament, the Council, the European Economic and Social Committee and the Committee of the Regions. Thematic strategy on the sustainable use of natural resources. $\operatorname{COM}(2005) 670$

CEC (2008) Communication from the Commission to the European Parliament, the Council, the European Economic and Social Committee and the Committee of the Regions on the Sustainable Consumption and Production and Sustainable Industrial Policy Action Plan. COM(2008) 397/3

Finkbeiner M, Schau MS, Lehmann A, Traverso M (2010) Towards life cycle sustainability assessment. Sustainability $2: 3309-3322$

Graedel TE, van der Voet E (eds) (2010) Linkages of sustainability. MIT Press, Cambridge

Guinée JB, Heijungs R, Huppes G, Zamagni A, Masoni P, Buonamici R, Ekvall T, Rydberg T (2011) Life cycle assessment: past, present, and future. Environ Sci Technol 45:90-96

Halog A, Manik Y (2011) Advancing integrated systems modelling framework for life cycle sustainability assessment. Sustainability 3:469-499

Hunkeler D, Rebitzer G (2005) The future of life cycle assessment. Int J Life Cycle Assess 10(5):305-308

Kates RW, Clark WC, Corell R, Hall JM, Jaeger JJ, Lowe I, McCarthy JJ, Schellnhuber HJ, Bolin B, Dickson NM, Faucheux S, Gallopin GC, Grübler A, Huntley B, Jäger J, Jodha NS, Kasperson RE, Mabogunje A, Matson P, Mooney H, Moore B, O'Riordan T, Svedin U (2001) Sustainability science. Science 292(5517):641-642

Klöpffer W (2003) Life-cycle based methods for sustainable product development. Int J Life Cycle Assess 8(3):157-159

Klöpffer W (2008) Life cycle sustainability assessment of products. Int J Life Cycle Assess 13(2):89-95

Koroneos CJ, Rokos D (2012) Sustainable and integrated development - a critical analysis. Sustainability 4:141-153

Lee N, Kirkpatrik C (2001) Methodologies for sustainability impact assessments of proposals for new trade agreements. J Environ Assess Policy Manag 3(1):395-412

Parkin S, Sommer F, Urens S (2000) Sustainable development: understanding the concept and the practical challenge. Eng Sustain 156 (ES1):19-26 
Seager TP (2008) The sustainability spectrum and the sciences of sustainability. Bus Strat Environ 17:444-453

Swarr T, Hunkeler D, Klöpffer W, Pesonen HL, Ciroth A, Brent AC, Pagan R (2011) Environmental life cycle costing: a code of practice. SETAC Press, Pensacola, ISBN 978-1-880611$87-6$
Upham P (2000) An assessment of the natural step theory of sustainability. J Clean Prod 8(6):445-454

Valdivia S, Ugaya CML, Sonnemann G, Hildenbrand J (eds) (2011) Towards a life cycle sustainability assessment. Making informed choices on products. ISBN: 978-92-807-3175-0 Paris 2011. Available at: http://lcinitiative.unep.fr) 